\title{
SARS-CoV-2 existence in different types of biological Specimens \& leading public health concern
}

\author{
Dr Priyanka Yadav*1 \\ ${ }^{1}$ Assistant Professor, Kanoria PG Mahila Mahavidyalaya, Jaipur, Rajasthan, India \\ *Corresponding author's email: priyanyadav1980@gmail.com
}

\author{
Article Type: Review
}

\begin{abstract}
There is a new public health crisis threatening the world with the emergence and spread of novel coronavirus (SARS-CoV-2). The outbreak of coronavirus disease 2019 (COVID-19), which originated in Wuhan, China, in December 2019, has been declared a public health emergency of international concern by WHO. Most patients infected with SARS-CoV-2 exhibited symptoms of fever, cough, myalgia, fatigue and shortness of breath. Many infected people may be asymptomatic. It is generally believed that airway exposure to respiratory droplets from an infected patient is the main transmission route of this disease. However, apart from respiratory source, other source specimens like faecal matter and urine could be possible for COVID-19 infectivity. The spreading other routes of the virus has been alarming sign, both for public and health care professionals. Understanding the spreading routes of SARS-CoV-2 is crucial for patient management and defining biosafety strategies for public and health care workers.
\end{abstract}

Keywords: SARS-CoV-2, COVID-19, 2019-nCOV, Shedding, Detection

\section{Introduction}

Severe acute respiratory syndrome coronavirus 2 (SARS- CoV-2) infection, which causes coronavirus disease 2019 (COVID-19), first emerged in China in December 2019 and has now spread worldwide, with a reported $60,16,976$ confirmed cases and 3,70,153 deaths as of 01 June 2020 according to WHO. ${ }^{[1]}$ The infection is typically characterized by respiratory symptoms, which indicates droplet transmission. It is accepted that disease is transmitted by inhalation or contact with virus infected material with incubation period ranges from 2 to 14 days. Now this source of infection is very well established i.e. it is transmitted through direct contact with respiratory droplets of an infected person (generated through coughing and sneezing). Individuals can also be infected from touching surfaces contaminated with the virus and touching their face (e.g., eyes, nose, mouth). For the same, real-time reverse transcriptase polymerase chain reaction (rRT-PCR) of nasopharyngeal or oropharyngeal swabs (respiratory secretion) typically has been used to confirm the clinical diagnosis.

Previous studies on SARS and MERS have demonstrated that coronaviruses could transit and thrive within the gastrointestinal system. ${ }^{[2][3][4][5][6]}$ Whether this novel corona virus can be potentially transmitted in other ways than by respiratory droplets, is unknown. Hence there could be possibility COVID-19 can be spread through other infected clinical specimens.

This could be a major concern for developing countries like India, where around 93322 active cases of coronavirus disease 2019 (COVID-2019) and 5394 reported deaths to date (assessed on June 01, 2020) in India. ${ }^{[7]}$ Hence it is important to take initial action to prevent further transmission, reduce the impacts of the outbreak and support control measures.

Therefore, in the current review, reported literatures for virus shedding in stool and urine sample of infected patients were assessed and summarized in table 1 . This would give insight in defining biosafety strategies and guidelines. 


\section{Search strategy and selection criteria}

A thorough search was conducted through the PubMed, Google scholar, ScienceOpen database and web-based portals to find articles published till April 30, 2020 with no limitations by starting date. Search is restricted to articles published in English, using the following keywords: "COVID19", "SARS-Cov-2", "2019-nCoV", "novel coronavirus", "coronavirus", "SARS 2", "feces", "faecal", "stool", "sewage", "rectal", "urine", "transmission", "Shedding" and "detection".

Relevant article titles, abstracts and full text articles from retrospective, prospective, observational/interventional, case reports, case series, meta-analysis and review papers published with relevant findings regarding the novel corona virus existence in different types of biological Specimens were reviewed. Studies were excluded for non-relevant data, had inappropriate topics and were not pertinent to the focused purpose of the review.

\section{Literature search review}

The literature search revealed various articles, of which appropriate articles were selected according to their abstracts and further reviewed focusing on stool and urine as test samples. These papers described epidemiological, laboratory, clinical complications, radiographic abnormalities, medical treatment as well as outcome data of patients with COVID-19. In addition, these publications also reported information about presence \& shedding of virus in different biological samples. About 22 publications (13 prospective studies, 6 case series \& 3 retrospective studies) were reviewed for presence of SARS-Cov-2 in urine samples of infected patients (Table 1).

During review of publication, it was found that some of the studies has limitations since sample collection timing \& method of detection was not uniformed like early collection or late during the course of illness. However, studies mentioned that biological samples were collected systematically when possible.

In these studies, approximately 1052 laboratory confirmed patients were enrolled \& 413 patients urine sample \& 687 patients stool samples tested for existence of SARS-CoV-2 in specimens. As per conducted search, SARS-CoV-2 presence were reported in urine sample of 10 patients \& stool sample of 261 patients.

Chen $\mathrm{Y}$ et al., reported that approximate $64 \%$ patients remained positive for viral RNA in feces after pharyngeal swabs turned negative and the duration of viral shedding from feces after negative conversion in pharyngeal swabs was 7 (6-10) days, regardless of COVID-19 severity. ${ }^{[8]}$

Ma X et al. found that $29.6 \%$ patients, all of whom were diagnosed with mild to moderate infection and discharged 1 to 2 weeks ago, showed positive PCR results in their stool but negative results in their respiratory specimens. ${ }^{[9]}$

As per continuous updates from scientific reports, asymptomatic infection is not uncommon. A recent study on the prevalence of COVID-19 demonstrated that 27.7\% laboratory confirmed cases did not have any symptoms of infection. An asymptomatic case had SARS-CoV-2 RNA detectable in faeces at least 9 days after viral clearance in the respiratory tract. It might be possible that asymptomatic infected with SARS-CoV2 go undetected and represent as important contributors to virus transmission in the community, causing the pandemic to propagate. ${ }^{[10]}$ Hence, these findings have implications for our understanding of SARS- CoV-2 transmission that asymptomatic cases may be shedding infectious virus and they could transmit it. ${ }^{[1]}$

Similar information was also reported by other authors i.e. clearance of viral RNA in patients' stools was delayed compared to that in oropharyngeal swabs. ${ }^{[12][13]}$ Prolonged virus shedding is observed in feces at the convalescent stage even more than 1 month, which raises a question concerning whether the gastrointestinal tract may be another site of viral replication. ${ }^{[14]}$ 
As per Wong SH et al. \& Tian Y et al., the tropism of SARS-CoV-2 to the gastrointestinal tract, have important implications to both patient care and infection control. Clinicians should be alert of the gastrointestinal manifestations of Covid-19, especially as they may occur before the onset of fever and other respiratory symptoms. ${ }^{[15][16]}$

Yeo $\mathrm{C}$ et al., reported that SARS-CoV RNA was found in the sewage water of two hospitals in Beijing treating patients with SARS. When SARS CoV was seeded into sewage water obtained from the hospitals in a separate experiment, the virus was found to remain infectious for 14 days at $4{ }^{\circ} \mathrm{C}$, but for only 2 days at $20^{\circ} \mathrm{C}$. ${ }^{[17]}$

Till now, the infection control and surveillance focus on respiratory system. The ignorance of SARSCoV-2 shedding from other body system may cause troubles in the disease control. Public health might be endangered by possible prolonged discharge of SARS-CoV-2 in extra-respiratory routes. ${ }^{[18]}$ Therefore, it can clinch that shedding of SARS-CoV-2 via other route should not be ignored as one of the possible transmission routes of the virus. 
Table 1: Existence of SARS Cov-2 in biological samples in selected publications

\begin{tabular}{|c|c|c|c|c|c|c|}
\hline Reference & Study type & $\begin{array}{c}\text { Total enrolled } \\
\text { patients }\end{array}$ & $\begin{array}{c}\text { Urine specimen } \\
\text { tested }\end{array}$ & $\begin{array}{c}\text { Urine sample tested } \\
\text { positive }\end{array}$ & $\begin{array}{c}\text { Stool sample } \\
\text { tested }\end{array}$ & $\begin{array}{l}\text { Stool sample } \\
\text { tested positive }\end{array}$ \\
\hline Wang W et al. ${ }^{[19]}$ & Prospective study & 205 & 72 & None & 153 & 44 \\
\hline Wang L et al. ${ }^{[20]}$ & Prospective study & 116 & 53 & 4 & None & - \\
\hline LingY et al. ${ }^{[12]}$ & Retrospective study & 66 & 58 & 3 & 66 & 11 \\
\hline Chen Y et al. ${ }^{[8]}$ & Prospective study & 42 & 10 & None & 42 & 28 \\
\hline Peng L et al. ${ }^{[21]}$ & Prospective study & 9 & 9 & 1 & 9 & 2 \\
\hline Cai J et al. ${ }^{[14]}$ & Case series & 10 & 5 & None & 6 & 5 \\
\hline Lescure FX et al. ${ }^{[22]}$ & Case series & 5 & 5 & None & 5 & 2 \\
\hline Pan Y et al. ${ }^{[23]}$ & Case series & 82 & 2 & None & 17 & 9 \\
\hline Zheng S et al [13] & Retrospective study & 96 & 96 & 1 & 96 & 55 \\
\hline WangTo et al ${ }^{[24]}$ & Prospective study & 23 & 18 & None & 23 & 4 \\
\hline Xie $\mathrm{C}$ et al. ${ }^{[25]}$ & Prospective study & 9 & 9 & None & 9 & 8 \\
\hline Young BE et al. ${ }^{[26]}$ & Case series & 18 & 10 & None & 8 & 4 \\
\hline Mondanizadeh $\mathrm{M}^{[27]}$ & Prospective study & 50 & 50 & None & 50 & 2 \\
\hline Huang Y et al. ${ }^{[28]}$ & Retrospective study & 16 & 16 & 1 & None & - \\
\hline Dona D et al [29] & Case Study & 2 & None & None & 2 & 2 \\
\hline Xiao F et al ${ }^{[30]}$ & Prospective study & 73 & None & None & 73 & 14 \\
\hline Liu J et al ${ }^{[31]}$ & Prospective study & 69 & None & None & 4 & 4 \\
\hline Ma X et al ${ }^{[9]}$ & Prospective study & 27 & None & None & 27 & 8 \\
\hline Yuan Y et al ${ }^{[32]}$ & Case series & 6 & None & None & 6 & 6 \\
\hline Xu Y et al [33] & Prospective study & 10 & None & None & 10 & 8 \\
\hline Wu Yet al ${ }^{[34]}$ & Prospective study & 98 & None & None & 74 & 41 \\
\hline Lei $\mathrm{Z} \mathrm{et} \mathrm{al}^{[35]}$ & Prospective study & 20 & None & None & 7 & 4 \\
\hline
\end{tabular}




\section{Discussion}

The global impact of this pandemic is yet uncertain. There are significant misconceptions and many obstacles in the way of eradicating of COVID-19 pandemic. SARS CoV-2 transmits as a droplet pathogen and considered as highly infectious agents and control measures recommended are those for category A agents (considered the most dangerous category of infection). Several prospective, retrospective and case studies have evident that some patients with SARS- CoV-2 infection have viral RNA or live infectious virus present in faeces and/or urine, which suggests that another possible route of transmission. Usefulness of recent evidence published in the context of existence of virus in other specimens for decision making in clinic as well as public health is doubtful. However, this review appraised epidemiological and clinical aspects of route of transmission and implementation of successful measures for preventing its spread in Indian populations at initial stages of this pandemic. As we know that greatest risk in COVID-19 is the transmission and it is important to break the continuity to prevent transmission of infection to other people.

\section{Declarations}

\subsection{Study Limitations}

none

\subsection{Acknowledgements}

none

\subsection{Funding source}

none

\subsection{Competing Interests}

No potential conflict of interest

\section{Human and Animal Related Study}

None

\subsection{Ethical Approval}

None

\subsection{Informed Consent}

None

\section{References}

1. WHO Coronavirus disease (COVID-19) outbreak situation. https://www.who.int/emergencies/diseases/novel-coronavirus-2019. Date accessed: June 01, 2020

2. Leung WK, To KF, Chan PK, Chan HL, Wu AK, Lee N, et al. Enteric involvement of severe acute respiratory syndrome-associated coronavirus infection. Gastroenterology 2003; 125 (4): 1011-1017. doi: 10.1016/s0016-5085(03)01215-0.

3. Cheng PK, Wong DA, Tong LK, Ip SM, Lo AC, Lau CS, et al. Viral shedding patterns of coronavirus in patients with probable severe acute respiratory syndrome. Lancet (London, England) 2004; 363 (9422): 1699-1700. doi: 10.1016/s01406736(04)16255-7. 
4. Wang XW, Li JS, Guo TK, Zhen B, Kong QX, Yi B, et al. Excretion and detection of SARS coronavirus and its nucleic acid from digestive system. World journal of gastroenterology 2005; 11 (28): 4390-4395. doi: 10.3748/wjg.v11.i28.4390.

5. Fehr AR, Perlman S. Coronaviruses: An Overview of Their Replication and Pathogenesis. In: Maier HJ, Bickerton E, Britton P, eds. Coronaviruses: Methods and Protocols. New York, NY: Springer New York; 2015: 1-23.

6. Zhou J, Li C, Zhao G, Chu H, Wang D, Yan HH, et al. Human intestinal tract serves as an alternative infection route for Middle East respiratory syndrome coronavirus. Science advances 2017; 3 (11): eaao4966. doi: 10.1126/sciadv.aao4966.

7. Ministry of Health and Family Welfare Government of India. Website: https://www.mohfw.gov.in/ Date accessed: June 01, 2020

8. Chen Y, Chen L, Deng Q, et al. The Presence of SARS-CoV-2 RNA in Feces of COVID-19 Patients. J Med Virol. 2020 Apr 3. doi: 10.1002/jmv.25825.

9. Ma X, Su L, Zhang Y et al., Do children need a longer time to shed SARS-CoV-2 in stool than adults?, Journal of Microbiology, Immunology and Infection, https://doi.org/10.1016/j.jmii.2020.03.010

10. Xing Y. Dynamics of faecal SARS-CoV-2 in infected children during the convalescent phase. Journal of Infection. DOI: https: //doi. org/10.1016/j.jinf. 2020.03.049

11. Jordan Hindson. COVID-19: faecal-oral transmission? Nature Reviews Gastroenterology \& Hepatology | https://doi.org/10.1038/s41575-020-0295-7

12. Ling Y, Xu SB, Lin YX, et al. Persistence and clearance of viral RNA in 2019 novel coronavirus disease rehabilitation patients. Chin Med J (Engl). 2020 Feb 28. doi: 10.1097/CM9.0000000000000774

13. Zheng S, Fan J, Yu F, et al. Viral load dynamics and disease severity in patients infected with SARS-CoV-2 in Zhejiang province, China, January-March 2020: retrospective cohort study. BMJ. 2020 Apr 21;369:m1443.

14. Cai J, Xu J, Lin D, et al. A Case Series of children with 2019 novel coronavirus infection: clinical and epidemiological features. Clin Infect Dis. 2020 Feb 28. pii: ciaa198. doi: 10.1093/cid/ciaa198.

15. Wong SH, Rashid NS Lui, Joseph JY Sung et al. Covid-19 and the digestive system. Journal of Gastroenterology and Hepatology doi:10.1111/jgh.15047.

16. Tian Y, Rong L, Nian W et al Review article: gastrointestinal features in COVID-19 and the possibility of faecal transmission. Aliment Pharmacol Ther. 2020;00:1-9.

17. Yeo C, Sanghvi Kaushal, Danson Yeo. Enteric involvement of coronaviruses: is faecal-oral transmission of SARS-CoV-2 possible? www.thelancet.com/gastrohep Vol 5 April 2020

18. He Y, Wang Z, Li F et al. Public health might be endangered by possible prolonged discharge of SARS-CoV-2 in stool, Journal of Infection (2020), doi: https://doi.org/10.1016/j.jinf.2020.02.031

19. Wang W, Xu Y, Gao R, et al. Detection of SARS-CoV-2 in Different Types of Clinical Specimens. JAMA. 2020 Mar 11. doi: 10.1001/jama.2020.3786.

20. Wang L, Li X, Chen H, et al. Coronavirus Disease 19 Infection Does Not Result in Acute Kidney Injury: An Analysis of 116 Hospitalized Patients from Wuhan, China. Am J Nephrol 2020. doi: 10.1159/000507471

21. Peng L, Liu J, Xu W, et al. 2019 Novel Coronavirus can be detected in urine, blood, anal swabs and oropharyngeal swabs samples. medRxiv 2020.02.21.20026179; doi: https://doi.org/10.1101/2020.02.21.20026179 
22. Lescure FX, Bouadma L, Nguyen D, et al. Clinical and virological data of the first cases of COVID-19 in Europe: a case series. Lancet Infect Dis. 2020 Mar 27. pii: S1473-3099(20)30200-0. doi: 10.1016/S1473-3099(20)30200-0.

23. Pan Y, Zhang D, Yang P, et al. Viral load of SARS-CoV-2 in clinical samples. Lancet Infect Dis. 2020 Apr;20(4):411-412.

24. WangTo KK, Tsang OT, Leung W, et al. Temporal profiles of viral load in posterior oropharyngeal saliva samples and serum antibody responses during infection by SARS-CoV-2: an observational cohort study. The Lancet Infectious Diseases.2020. 10.1016/S1473-3099(20)30196-1.

25. Xie C, Jiang L, Huang G, et al. Comparison of different samples for 2019 novel coronavirus detection by nucleic acid amplification tests. Int J Infect Dis. 2020 Feb 27; 93:264-267.

26. Young BE, Ong SWX, Kalimuddin S, et al. Epidemiologic Features and Clinical Course of Patients Infected With SARS-CoV-2 in Singapore. JAMA. 2020 Mar 3. doi: 10.1001/jama.2020.3204.

27. Mondanizadeh M, Rahimi E, Sarmadian H, et al. Evaluation of SARS-CoV-2 existence in blood, urine, and rectal swab in positive patients with different virus titers. 12 April 2020, (Version 1) available at Research Square doi. 10.21203/rs.3.rs20499/v1

28. Huang Y, Chen S, Yang Z, et al. SARS-CoV-2 Viral Load in Clinical Samples of Critically Ill Patients. Am J Respir Crit Care Med. 2020 Apr 15. doi: 10.1164/rccm.202003-0572LE.

29. Dona D, Chiara Minotti, Paola Costenaro. Fecal-oral transmission of SARS-Cov-2 in Children. The Pediatric Infectious Disease Journal. DOI: 10.1097/INF.0000000000002704

30. Xiao F, Tang M, Zheng X et al. Evidence for Gastrointestinal Infection of SARSCoV-2. Gastroenterology 2020;158:1831-1833

31. Liu J, Xiao Y, Shen Y et al. Detection of SARS-CoV-2 by RT-PCR in anal from patients who have recovered from coronavirus disease 2019 . doi: 10.1002/jmv.25875.S

32. Yuan Y, Wang N, Ou X et al. Caution should be exercised for the detection of SARSCoV-2, especially in the elderly. J Med Virol. 2020;1-8.

33. Xu Y, Xufang Li, Bing Zhu et al. Characteristics of pediatric SARS-CoV-2 infection and potential evidence for persistent fecal viral shedding Nature Medicine . Vol 26, April 2020; 502-505

34. Wu Y, Guo C, Tang L et al. Lancet Gastroenterol Hepatol 2020 Published Online March 19, 2020 https://doi.org/10.1016/S2468-1253(20)30083-2

35. Lei Z, Cao H, Jie $\mathrm{Y}$ et al. A cross-sectional comparison of epidemiological and clinical features of patients with coronavirus disease (COVID-19) in Wuhan and outside Wuhan, China. Travel Medicine and Infectious Disease, https:// doi.org/ 10.1016/j. tmaid. 2020. 101664 